\title{
Las trampas de la identidad bajo el designio del logos
}

\author{
Gonzalo Federico Zubia \\ Centro de Estudios en Historia, Cultura y Memoria (CeHCMe) UNQ UNJu / \\ CONICET, Quilmes, Buenos Aires, Argentina. \\ Email: gfzubia@hotmail.com
}

\begin{abstract}
Resumen: El diálogo intercultural devenido en monólogo legal en el espacio público, en tiempos de políticas de la identidad, atraviesa la trama de la disputa territorial por el sentido del lugar en las Salinas Grandes, Jujuy, Argentina. Allí las comunidades indígenas resisten a que en sus territorios se realicen actividades de exploración y explotación de litio, mineral estratégico para la producción de baterías electrónicas, talón de Aquiles sobre el que se sostiene el tecnologicismo contemporáneo. En esta disputa, la genealogía analítica entrama procesos históricos más amplios y plantea las trampas de la identidad como procesos de encapsulamiento de la alteridad radical y la ecualización de la diferencia. Bajo el designio del logos moderno, estas trampas subsumen interpretaciones diferenciadas del lugar, limitándolas a su enunciación bajo el lenguaje positivo con la consecuente pérdida de radicalidad. Se abre entonces la necesidad de un proyecto político crítico y oposicional para superar estas trampas.
\end{abstract}

Palabras claves: identidad; logos; ecualización; diferencia.

\section{The traps of identity under the design of logos}

\begin{abstract}
The intercultural dialogue becomes a legal monolog in public space, in times of identity politics, crosses the plot of territorial dispute over the meaning of the location in Salinas Grandes, Jujuy, Argentina. There, the indigenous communities resist the taking place in their territories of exploration and exploitation of lithium, a strategic mineral for the production of electronic batteries, the Achilles heel on which relies contemporary technology. In this disputation, the analytical genealogy interweaves broader historical processes and poses the traps of identity as encapsulation processes of radical alterity and difference equalization. Under the design of modern logos, these traps subsume differentiated interpretations about the location, limiting them to its enunciation from positive language with the consequent loss of radicalism. This opens the need for a critical and oppositional political project to overcome these traps.
\end{abstract}

Key words: identity; logos; equalization; difference.

\section{As armadilhas da identidade no âmbito do logos}

Resumo: O diálogo intercultural que se tornou monólogo legal no espaço público, em tempos de políticas da identidade, perpassa o enredo da disputa territorial sobre o significado de lugar nas Salinas Grandes, Jujuy, Argentina. Aí as comunidades indígenas resistem a que em seus territórios se realizem atividades para a prospecção e exploração de lítio, mineral estratégico para produzir baterias 
eletrônicas, calcanhar de Aquiles sobre o qual se sustenta o tecnologicismo contemporâneo. Nesta disputa, a genealogia analítica entrelaça processos históricos mais abrangentes e levanta as armadilhas da identidade como um processo de encapsular a alteridade radical e a equalização da diferença. Sob o âmbito do logos moderno, estas armadilhas subsomem interpretações diferenciadas limitando-os a sua declamação sob uma linguagem positiva, com a consequente perda de radicalidade. Então fica aberta a necessidade de um projeto político crítico e de oposição para superar essas armadilhas.

Palavras-chave: identidade; logos; equalização; diferença.

$$
* * *
$$

Tenemos que realizar un análisis sólido, tan minucioso que resulte completamente irrefutable para denunciar las ofensas

y las injurias que han acompañado y acompañan ( con una violencia creciente) nuestras largas existencias.

Lo haremos.

Vamos a generar un gran manual histórico del maltrato y de la postergación.

Esa es mi intención. Hoy. Diamela Eltit. Impuesto a la carne.

\section{Del pronunciamiento de las trampas}

Hay una trampa de la que debemos estar atentos para poder sortear; una trampa que hace de la identidad un lugar estable y estabilizado; que captura el movimiento y lo ancla; que hace de la divergencia una nueva facción incorporando su tensión pero comprimiendo su potencial radical. Ésta es la ecualización de la diferencia (Segato 2007): el ajuste a determinados valores de reproducción a fin de igualar la diferencia a su emisión originaria, a su designación. Un proceso que busca la reproducción en alta fidelidad, la operación de la igualación, en la experiencia simétrica para unos y otros, y que opera desde el momento en que somos nombrados y hacemos de ese nombre carne de nuestro cuerpo. Marcas en nuestras frentes como las que dejó el padre Antonio Isabel en los Aurelianos aquel miércoles de ceniza en "Cien años de soledad”, de García Márquez, que no se borran ni siquiera con tierra ni estropajo, ni con piedra pómez ni lejía. Marcas que nos designan y que antes que nada dicen quiénes somos. Son esos lugares que configuran marcas de nuestra identidad estabilizada desde donde somos leídos y encasillados y que también circunscriben lo que podemos decir y, fundamentalmente, los modos en que podemos decirlo. "Estrellas de David” que marcan discursos y recorridos con los que "debemos” movernos para ser percibidos. De eso se trata la trampa que denunciamos aquí, en tanto operación contemporánea de discusión. Y de allí también las estrategias para sortearla en tanto proyecto político de la disidencia. No quedar entrampados -0 al menos no inocentemente- es entonces la 
propuesta que se abre como opción en este texto.

Este es el pronunciamiento que sostendré a lo largo del presente trabajo -la tesis, diríase- y del que la crítica cultural debe hacerse cargo planteando interrogantes que des-ubiquen los sentidos estabilizados. Pronunciamiento que se articulará en el análisis -y también sobre el análisis mismo, es decir, de nuestras propias epistemologías- en torno a procesos extractivos en territorios indígenas -y no "pueblos originarios” según lo planteado por Rivera Cusicanqui (2010)ㄹ - en las Salinas Grandes y Laguna de Guayatayoc (en adelante Salinas Grandes), Provincia de Jujuy, al norte de la Argentina, escenario intercultural de confrontación y disputa por el sentido y uso del espacio y por cómo éste es pensando desde distintas formas históricas. Pero las Salinas Grandes constituyen también un espacio donde la trampa denunciada se mantiene como figura espectral que tensiona la discusión asignando lugares de enunciación y los términos en que ésta se desenvolverá. Del análisis de esta presencia/figura me ocuparé en lo que sigue.

El presente texto tiene por objeto poner en discusión las operaciones de esencialización de identidades en tiempos de "políticas de la identidad” (Segato 2007), analizando cómo éstas operan en los procesos extractivos de recursos naturales en territorios indígenas en Jujuy. La discusión que se propone es una crítica a los modos de estabilización de la diferencia que se produce cuando concepciones diferenciadas del territorio son normalizadas a través de una figura determinada; en este caso, a través del derecho a la posesión de la tierra. Esta normalización sucede cuando interpretaciones diferenciadas de los "lugares” (Santos 2000), como la de los pueblos indígenas y su conexión con la Pachamama o Madre Tierra, tensionan interpretaciones hegemónicas como la de "recursos naturales” según la perspectiva Estado-céntrica. Esta tensión se resuelve en términos de nominalización y normalización de la diferencia cuando la operación estabiliza el sentido radical y lo circunscribe a una forma de enunciación. De allí que la relación cultural con el "lugar" se circunscriba a una disputa por la posesión legal de un territorio, el indígena, cuando su configuración original, primaria, es más amplia y compleja: el sentido del "lugar" como forma antropológica. Esta operación es la que resuelve el conflicto, domesticando la diferencia y generando limitadas opciones políticas para la resistencia.

El texto se organiza del siguiente modo: en un primer apartado, se expone el tema de investigación de base referente a la disputa por los usos y sentidos del territorio en las Salinas Grandes, y su articulación analítica con un problema más amplio denotado en el recorrido investigativo y que tiene que ver con la escisión entre "naturaleza” y “cultura” como categorías autónomas en la modernidad. Este apartado abre una serie de interrogantes acerca del diálogo con la diferencia que puede leerse en el conflicto ambiental en análisis. En el segundo apartado, se presenta la problemática en su faceta legal, tal cual es organizada y canalizada la demanda por los usos de la tierra articulando la exposición con el análisis de la ecualización y la traducción de la diferencia en el espacio público. El tercer apartado da cuenta de cómo el conflicto se desenvuelve bajo una organización moderna 
de participación en el espacio público bajo un "logos” único: la razón, y cómo ésta obtura el diálogo desde otros “logos” alternativos. Este mismo apartado pone en discusión el pluralismo jurídico como alternativa ante la disyuntiva de la disputa por el territorio. El cuarto apartado pone en tensión el "logos" de este espacio público moderno con otros "logos" culturales indígenas, entre monó-logos y diá-logos, discutiendo también la estabilización que se ha hecho de "logos" socio-culturales indígenas como la Pachamama. El quinto apartado realiza una crítica del pensamiento moderno para pensar la diferencia, en tanto aporte crítico a las corrientes decoloniales y el compromiso político de la investigación. Por último, a modo de conclusión inconclusa, se realiza un cierre propositivo para seguir pensando la ecualización de la diferencia.

\section{De la "naturaleza" como "recurso" o del problema de investigación}

Pesa sobre nosotros -todavía- una escisión histórica entre la "naturaleza" y la "cultura" como lugares autónomos, relacionados en mayor o en menor medida -según diferentes perspectivas-, pero siempre independientes. Una bifurcación abierta en la modernidad, acelerada por el capitalismo, que creó para cada unidad ontológica una epistemología propia como gestión del conocimiento: las ciencias biológicas y las ciencias humanas (Murillo 2012). Desde esta bifurcación, se construyeron las catedrales del conocimiento para las ciencias y, desde sus altares, las tecnologías con las que se gestionó la "cultura” en tanto "sociedad", y la "naturaleza” en tanto "recurso" o "bien natural” que puede sostener a la primera. Gestión política desde la que se construye el territorio y la nación en una doble operación: la construcción de la ficción del "ciudadano" como igualación de la sociedad y de la "tierra como recurso" como igualación del ambiente en la topografía de la diferencia (Zubia 2012).

El peso de tal escisión histórica todavía nos causa hipermetropía: nos cuesta ver la densidad de la complejidad en la proximidad ya que la imagen se forma más allá de nuestras retinas. Esta escisión se nos presenta como obstáculo para pasar de un naturalismo ingenuo a otras formas de relación entre la "naturaleza" y la "sociedad", y para llegar a comprender formas otras de esta relación posible, otras ontologías (Descola 2012) como la de la Pachamama para los pueblos andinos. Estas lecturas genealógicas heterónomas son los puntos de encrucijadas claves para entender los conflictos ambientales que se generaron en las últimas décadas en Latinoamérica, donde se pueden leer “lenguajes de valoración” diferenciados, al decir de Martínez-Alier (2004), acerca de la naturaleza y el ambiente (Svampa 2008).

Desde estas coordenadas analíticas es posible analizar y reflexionar, por ejemplo, las transformaciones que en el paisaje cultural (Chiozza y Carballo 2009; Souto 2011) generaría la transición de la tecnología produc- 
tiva en las Salinas Grandes, y los modos de resistencia de las comunidades indígenas en que sucedan estos cambios. En esta coyuntura, la problemática se inicia a partir del interés del Gobierno Provincial, del Gobierno Nacional y de empresas extractivas de capitales internacionales por iniciar la extracción de litio en la zona de las salinas -rica en ese mineral-, en lo que se conoce como "fiebre del litio" (Gallardo 2011). Se considera que las Salinas Grandes, el Salar de Uyuni en Bolivia y el Salar de Atacama en Chile constituyen la reserva más grande en el mundo de este mineral, en lo que se conoce como el “triángulo del litio". El mineral se convierte entonces, dada la economía globalizada y el tecnologicismo contemporáneo, en el recurso estratégico para la producción de batería para equipos electrónicos y, en los últimos años, los autos a batería, última promesa para revertir la polución ambiental generada por otros combustibles fósiles.

Este interés de explotación va a contramano del uso que hacen del Salar las comunidades indígenas de la zona, dedicadas a la explotación sustentable a través de la "cosecha" artesanal y comercialización de la sal en pequeña escala. De tal forma, se inicia una disputa entre distintos actores por el uso del territorio; una discusión en torno al "desarrollo" y la “innovación”, la inclusión en el mercado internacional a través del litio y los ingresos de dinero que eso implicaría para la provincia en su conjunto; una disputa por la hegemonía de los sentidos del lugar (Williams 1997), el territorio y el ambiente.

Esta discusión ha generado, desde la parte local, procesos de organización social asamblearia, movilización y acción colectiva² que las comunidades indígenas locales vienen realizando en tanto forma de resistencia a lo que consideran una amenaza a su forma de vida (MCOCSGLG 2011; Aguilar y Zeller 2012), además de la recurrencia a tribunales nacionales e internacionales e incluso la visita de un Relator Especial de Naciones Unidas $^{3}$ para legitimar la denuncia de las comunidades indígenas (Anaya 2012). Hay entonces, en todo este proceso, una forma de sostener la disputa en términos legales del derecho: derecho a la tierra, derecho a la identidad, derecho a la cultura. Se trata de enunciar el problema en una serie determinada de discursos pre-formateados.

Este escenario de disputa abre una serie de interrogantes: $\dot{¿}$ se pueden defender los territorios indígenas, los pueblos y sus culturas, a partir de los términos del lenguaje hegemónico? ¿De ese lenguaje modernista que se alía a la ciencia -coetáneas en el mismo proyecto- y que no ve en esta posibilidad de explotación del suelo sino una oportunidad de "desarrollismo social” como nuevo mito del crecimiento (Machado et al. 2011)? ¿Cuáles son las trampas que este discurso hegemónico presenta en la defensa de los territorios en disputa? ¿Puede el Estado comprender la existencia de etnoterritorios (Barabas 2004), de geografías simbólicas diferentes (Escobar 2001)? Y fundamentalmente, ¿cómo es el diálogo con esa diferencia?

El interés de estas cavilaciones, en las coordenadas propuestas, es reflexionar acerca de cómo se produce ese diálogo, esa interacción, entre 
dos discursos que son diferentes: el discurso de un Estado moderno que avala el desarrollo vinculado a la ciencia y tiene un lenguaje y una serie de categorías con las que enuncia el tiempo y el espacio, y otro lenguaje que tiene otra perspectiva, otra cosmovisión, otro simbolismo y, consecuentemente, otro tiempo y otro espacio (Santos 2000). Es necesario entonces realizar una genealogía (Foucault 2002) que reconstruya los indicios (Ginzburg 1999) de la intersección de estas dos ontologías diferentes que Escobar (2011) identifica como pachamámica y modérnica, de sus debates, de los procesos de identidad construidos históricamente y desde las cuales se piensa la alteridad. Una propuesta que tiene por objeto el reconocimiento de otras historias del ambiente -al decir de Worster (2008)- y que, desde la diferencia, permita pensar también cuál es la historia moderna de nuestras epistemes.

En lo que sigue, reflexionamos sobre estos interrogantes problematizando ensayos de respuesta desde contextos situados y específicos, no para buscar respuestas universales a las problemáticas locales sino más bien para ensayar alternativas de transformación social particulares que merecen ser analizadas como tal.

\section{La emergencia de la demanda indígena en las Salinas Grandes}

Lo que acontece en las Salinas Grandes en torno a la disputa por la explotación de litio es una muestra más de procesos económicos y políticos que los gobiernos populistas latinoamericanos han implementado en los últimos años. Bajo la lógica "desarrollista” y el designio del pleno empleo del Estado Benefactor, los gobiernos sudamericanos están avanzando ampliamente en la extracción de sus recursos naturales. Tómense como referencia, por ejemplo, los grandes proyectos multinacionales de la Iniciativa para la Integración de la Infraestructura Regional Sudamericana (IIIRSA) de planificación, inversión y construcción de grandes obras interestatales para conectar áreas que resultaban más inaccesibles a la producción y comercialización. No resulta casual entonces que dos de los proyectos de la IIIRSA se ubiquen en la zona de las Salinas Grandes: el nodo multimodal Susques ${ }^{4}$ y el acceso al Paso de Jama (Ruta Nacional $N^{\circ} 52$ - empalme Ruta Nacional $N^{\circ} 9$ - límite con Chile) ${ }^{5}$, ambos del Eje Capricornio, proponen el desarrollo de toda la zona del trópico a partir del mejoramiento de la infraestructura de transporte que facilite el acceso a la zona de referencia. De este modo, lugares que antes habían quedado marginados del "desarrollo" hoy se ven incluidos a procesos de globalización a través de la infraestructura y la comercialización. La extracción de los recursos naturales ahora se ve acelerada en zonas que se habían organizado históricamente con otras economías más artesanales.

Es esto lo que sucede en las Salinas Grandes, territorio habitado por 33 comunidades kollas que hicieron de ese lugar no sólo un espacio de 
hábitat sino también un espacio productivo a pequeña escala, sustentable diríase: la "cosecha” de sal. Esta práctica productiva es lo que da identidad a la zona y es la fuerza ocupacional de los pueblos alrededores de las Salinas. Práctica que, ante la explotación del litio, seguramente se transformaría. Es por ello que su resistencia a los proyectos extractivos consiste más bien en defender sus formas de vida, sus prácticas locales, sus interpretaciones del lugar, sus fuentes de agua, la Pachamama. ¿Y cómo hacerlo? ¿Cómo revestir de “derecho” algo que escapa a la lógica positiva? ¿Cómo revestir de derecho un sentimiento por el lugar, por el paisaje?

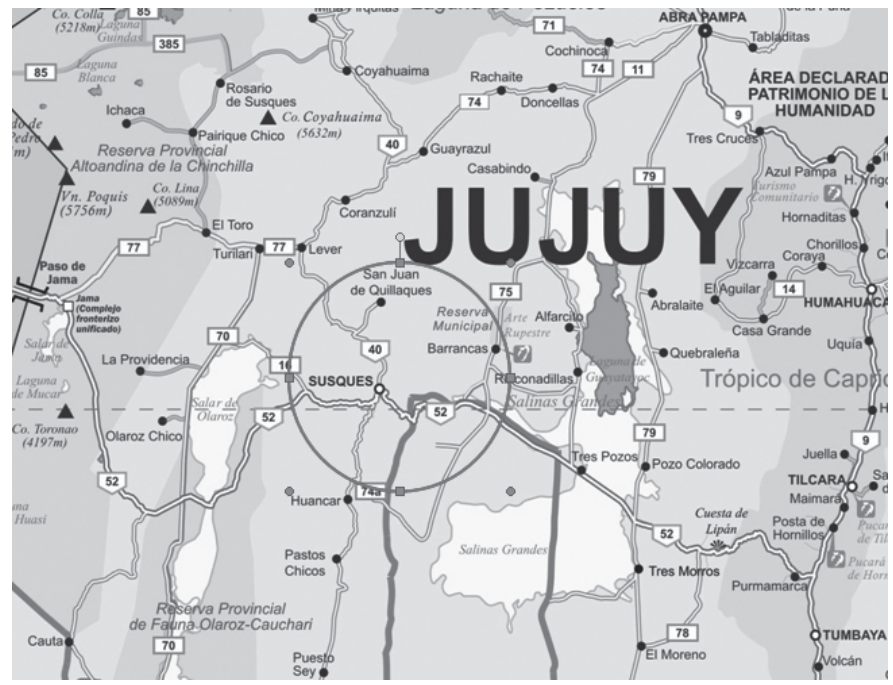

Mapa 1: Detalle de la zona de referencia.

Diseño: Secretaría de Turismo de la Provincia de Jujuy.

Detalle: En el Paso de Jama se ubica el Nodo Multimodal Susques y atravesando toda la zona la Ruta Nacional $\mathrm{N}^{\circ} 52$, ambos con financiamiento de la Iniciativa IIRSA. Y alrededor del salar las comunidades de Abralaite Lipan, Tres Pozos, El Moreno, Rinconadilla, Alfarcito, Pozo Colorados, entre otras consignadas en el diseño de éste mapa.

En esta coyuntura, la emergencia de la demanda indígena por la defensa del territorio en Jujuy se "traduce" a su faceta legal en el pedido de amparo por derecho a consulta de las comunidades indígenas avalado por el Convenio $\mathrm{N}^{\circ} 169$ de la OIT, a partir del cual las mismas reclaman participación. La denuncia específica es la siguiente: las 33 comunidades de la zona de las Salinas Grandes denuncian actividades de exploración de litio en sus territorios, y demandan al Estado Provincial en tanto éste -presuntamentebrindó autorización para la realización de la exploración minera en la zona. La denuncia se basa entonces en que el Estado Provincial no respetó el 
debido proceso de consulta a los pueblos indígenas para el otorgamiento de los permisos correspondientes. Esta disputa llegó en 2010 a la Corte Suprema de Justicia de la Nación ${ }^{6}$ que, tras una audiencia pública en marzo del 2011 en la que se convocó a ambas partes -33 comunidades demandantes y el Gobierno de la Provincia de Jujuy-, rechazó el pedido por falta de fundamento a principios del 2013. No había pruebas que dieran cuenta de la vinculación con la actividad de exploración primaria con el Gobierno Provincial.

En esta escena podemos leer al menos dos operaciones complejas que hacen a la ecualización de la diferencia. Una de ellas es la de traducibilidad: la de convertir -y convertirse en- un conjunto de sentimientos en un lenguaje para poder ser entendidos y enunciados. Si antes la pregunta era por la defensa del territorio y la estrategia del cómo hacerlo, la respuesta única posible parece ser la del derecho. La de traducir-se en los términos del derecho positivo, a esa forma de lenguaje universal buscando en él aquellas formas que más se acercan a los pareceres propios y usarlos para enunciar-se. Hay en esta operación un desplazamiento del lugar propio que ocupan los pueblos indígenas hacia el lugar del Estado en el derecho, el lugar Estado-céntrico. La traducción es eso: un desplazamiento del lugar original hacia otro ya no propio, un lugar ajeno que se ocupa para poder ser enunciado. Entonces, la traducibilidad del conflicto en su faceta legal -el pedido de amparo por la defensa del territorio- es la ecualización de la diferencia para convertirla en un sustento pre-interpretado dado los márgenes posibles de una actuación.

La segunda operación, íntimamente vinculada a la anterior, tiene que ver con el rechazo del pedido de amparo por falta de fundamento. ¿Cómo operan aquí los fundamentos? Los fundamentos pasan a ser la prueba positiva, objetiva diríase, que da base al derecho. En línea con lo que se viene desarrollando, traducir el conjunto de interpretaciones acerca de cómo el territorio es explorado por empresas mineras todavía sin permiso de exploración (COAJ 2012), y cómo estas actividades cuentan con el beneplácito del Gobierno Provincial, constituye todo un desafío para los pueblos locales. ¿Cómo poder dar cuenta de los ojos de agua-fuentes de agua- abiertos por las exploraciones mineras que dañan el salar? ¿Cómo poder dar cuenta de las huellas de neumáticos que atraviesan el salar y que conectan los lugares de exploración con salidas alternativas a los caminos habituales de ingreso? ¿Cómo no vincular estas actividades de exploración privada sin autorización con el Gobierno, si éste es pro-minero ${ }^{7}$ en su gestión y hace de la minería un motor del desarrollo? ¿Cómo convertir todo este conjunto de pareceres, producto del recorrido detenido por el salar, de su práctica de hábitat y producción, y traducirlo a una prueba legal? Esos pareceres, aunque por derecho propio enuncien una posición, no sirven de fundamento legal para dar cuenta de la exploración de litio en los territorios de las comunidades indígenas, como se ha visto. La traducibilidad de una interpretación cultural no sólo del territorio, sino de la actividad explorativa ilegal, en una prueba positiva también constituye parte de la ecualización. 
Y aquí también opera la hipermetropía antes comentada: la escisión entre "sociedad" y "naturaleza" como parte del mismo problema. Tal como advierte Zaffaroni (2011), el antropocentrismo que dominó el pensamiento filosófico jurídico moderno hizo de la naturaleza un lugar pasible, sujeto al control de la sociedad; pero la forma de habitar el espacio por las comunidades indígenas da cuenta de otras especialidades y otras experiencias de relación con la "naturaleza", otras otredades que también han quedado a oscuras en el lenguaje moderno del derecho positivo.

La potencialidad de la disputa intercultural es reducida entonces en su radicalidad al ser normalizada en el lenguaje uniforme del derecho positivo sentado sobre las bases del ejercicio de una ciudadanía simétrica que disuelve las identidades incongruentes. Si la alteridad radical como veta del conflicto se manifiesta en la disputa territorial, su ecualización en el derecho positivo da cuenta de una membrecía ciudadana como única modalidad de participación posible en el espacio público (Habermas 1990). De eso tratan las trampas que aquí se analizan.

\section{De logos, ensambles y espacios}

La ecualización de la diferencia en tanto trampa discursiva se sostiene sobre el ensamble histórico de la modernidad a partir de la articulación entre la ciencia y el Estado como modo significativo de gestión del conocimiento y lo que éste produce en términos de control, tanto en la sociedad y la población, por un lado y por otro, en el territorio, la naturaleza y el ambiente. La emergencia de un "logos” producto de ese ensamble histórico, la razón, y su configuración como hegemónico y universal bajo determinado proyecto político, es la que permite el entramado que da origen al dispositivo como complejo colonizador de la diferencia (Fornet-Betancourt 2006 y 2011). Es la razón y la racionalidad las que se imponen como único "logos" posible, única moneda de cambio en la economía de intercambios simbólicos (Bourdieu 2008), a partir del cual se produce la ecualización de la diferencia hasta allanarla y convertirla en un sustento plano como operación de anulación de la alteridad radical y su disolución en la estandarización universal. Bajo esta forma de tratamiento de la diferencia, la alteridad no tiene "razón de ser" sino que más bien la razón es la constitutiva para "ser” como única posibilidad.

En esta configuración histórica, el "logos" de la razón alumbra el espacio público dejando en la oscuridad otros "logos" posibles (FornetBetancourt, 2006). Bajo la luz de la razón, se impone como condición un lenguaje positivo para habitar tal espacio, para formar parte de él. En ese espacio público, solamente se puede hablar en esos términos que son los que generan la ciudadanía, el derecho y un tipo de conocimiento específico. Quienes no puedan ajustarse a su uso, no pueden hablar en ese espacio (Fraser 1997).

La trampa que este dispositivo impone a la emergencia organizada de la diferencia -léase movimientos sociales de pueblos indígenas- está 
dada justamente por los límites y posibilidades de enunciación de su posición bajo ese lenguaje único que es producto de aquel ensamble histórico: el lenguaje del derecho positivo, que tiene como epicentro el "logos" histórico de la razón, dominio bajo el cual sólo es posible enunciar determinadas posiciones, jugar determinadas acciones, ensayar determinadas tácticas. Flexible en tanto dispositivo (Foucault 2002), éste resulta tramposo como opción política radical ante la urgencia por la defensa del territorio. Y es acá cuando, en la pregunta que se hacía anteriormente referida a las formas en que se produce el diálogo, queda al menos sospechada una respuesta: bajo la ecualización de la diferencia.

La trampa, el "logos”, el ensamble histórico, el espacio público: todas configuraciones de un escenario que hacen posible poder enunciar una voz, una posición. Magma de articulaciones heterónomas y heteróclitas, en la defensa por los territorios se inter-sectan todas estas genealogías. Y un análisis cultural de los acontecimientos en las Salinas des-enhebra los múltiples artilugios que traman la trampa y develan su destino: la ecualización de la diferencia está dada entonces por asumir como propio y único posible el horizonte que tales intersecciones plantean. Es decir, asumir la disputa por la defensa del lugar desde el derecho positivo como horizonte de perspectiva sin poder poner en cuestionamiento su genealogía histórica y su génesis en el ensamble moderno. Asumir que la disputa sólo puede resolverse "legalmente", en una Corte Provincial, Nacional o Internacional, y establecer aquí el horizonte de perspectiva para la esperanza de la emancipación, es hacer de esa marca carne en nuestros cuerpos. Caer en la trampa de la ecualización es aceptar el lugar sin protestar; es también convertir la radicalidad de una acción en un proceso uniforme de ejercicio de la ciudadanía bajo el designio legal; es aceptar unívocamente que la "legalidad” es la única voz que puede oírse en el espacio público moderno.

Podría contra argumentarse aquí, sin duda, que un pluralismo jurídico puede ser el horizonte de perspectiva superador de la coyuntura que el problema propuesto plantea. No obstante, nuevamente hay que preguntarse cómo opera el proceso de domesticación de la diferencia en las diversas formas de pluralismo jurídico (Segato 2011). Preguntarse realmente si son formas abiertas al reconocimiento de la diferencia o si son formas de aplanamiento de la radicalidad. Preguntarse, por ejemplo, cuán predispuesto está el Estado en re-conocer los etnoterritorios en sus formas, planteado por sus habitantes -las comunidades-, y cómo éstos pueden convivir con la cartografía del territorio nacional. Es justamente allí, en las Salinas Grandes, donde antes el Estado no veía más que un desierto de sal y ahora ve el recurso estratégico para el desarrollo a través de la producción de baterías de litio, que la pregunta por las formas de diálogo con los pueblos indígenas pone en jaque las concepciones modernas del espacio, del desarrollo, de la sustentabilidad y hasta de las formas etiquetadas de interculturalidad.

Por otra parte, el pluralismo jurídico tiene como tensión inherente los categoriales universales propios de la jurisprudencia positiva. Esta tensión se manifiesta entonces entre la emergencia de categoriales particulares, 
situados, y la jurisprudencia universal, de raigambre en el mismo ensamble moderno antes comentado. Sostener el particularismo constituye el desafío para sortear la trampa que como figura espectral también se mantiene en el pluralismo jurídico. En todo este contexto, tal vez, la única alternativa política viable sea hacer implosionar ese único "logos" posible y dar cuenta de la emergencia de otros "logos", productos de otros contextos específicos y particulares. Ese es el proyecto que se propone a continuación.

\section{De diálogos y otros logos}

En el escenario descrito en Jujuy, dialogar con la Pachamama resulta un imperativo político para comprender las acciones de resistencia pero también para ver que allí sólo se nos muestra una veta de la diferencia, la punta del iceberg, una otredad que se hace evidente sólo parcialmente, que nos interpela y de la que tenemos mucho por aprender para entender los procesos históricos de las epistemes con las que trabajamos. Es en el diálogo que podremos aprender, tanto de esa otredad como de nosotros mismos (Bartolomé 2012), y acá es donde el análisis se analiza a sí mismo. Pero ¿qué implica dialogar con la Pachamama?

Como proyecto político, supone antes que nada el reconocimiento de otros "logos" que convergen en el diá-logo. Lugares diferentes, historias diferentes, “topos” culturales diferenciados, al decir de Panikkar (2007), que se encuentran en un diálogo diatópico, frente al cual se requiere de una hermenéutica adecuada de entendimiento para que la ecualización de la otredad no sea una operación que tiña y reemplace el diá-logo por un monólogo. Para que la operación de desplazamiento de un logo hacia el diálogo no sea colonizadora -la trampa-, es necesario reconocer la transitividad y el cambio, la sinergia que el movimiento produce. El reconocimiento del devenir del "logo" es entonces el fundamento de la renuncia por el universalismo y su apuesta a un situacionismo específico; una entrega íntima al terreno de los flujos y devenires que moviliza las certezas y nos deja en el campo de la incertidumbre. Habitar la incertidumbre es entonces el desafío que esta perspectiva propone.

Ahora bien, lo que vale como crítica para el "logos" moderno de la razón y su búsqueda de la estabilidad y la estabilización, y la forma categorial de universalismo histórico con el que éste opera, también vale para lo que se ha hecho de otros "logos" bajo el discurso hegemónico. Esas otras operaciones de ecualización en la episteme científico-social han enunciado los otros "logos" desde un lenguaje inflexible y diseccionador de la otredad que participa de la mono-modelización cultural. Con esto, me distancio de la máxima academicista/positivista/modernista que plantearía, para la empresa propuesta, una definición irrestricta de lo que se entiende por Pachamama. ¿Cómo es posible dialogar con ésta? La respuesta, de cuño academicista, plantearía que la Pachamama es parte del culto de los pueblos indígenas andinos de la parte central del continente sudamericano. La plantearía en términos de cosmovisión andina 
(Merlino y Rabey 1993), presentando la Pachamama como un simbolismo localista propio de una región determinada.

El proyecto aquí propuesto reniega de estas interpretaciones que no hacen más que aislar la diferencia en el diálogo, reduciéndola en una exotización antropológica. La búsqueda de "un" -uno solo- significado de Pachamama no hace más que reproducir una operación de estabilización, de anclaje, según lo advirtieran Deleuze y Guattari (2002). Esa estabilización es la trampa, es la identidad estabilizada y domesticada con la cual se aplana la radicalidad y su potencial.

Sortear esa trampa es pensar la Pachamama desde una etnografía (Guber 2001), desde una doble hermenéutica (Giddens 1993), y reflexionar no sobre cómo ésta opera como significado estabilizado, sino más bien sobre la cotidianidad de la práctica comunitaria, en la relación con el ambiente, la inherencia de la cultura con su territorio, en su oralidad (Rivera Cusicanqui 2008). En este último lugar, por difuso que nos parezca, la Pachamama opera como otro "logos" posible, como otro espacio, ya no aquel primer espacio público moderno, sino más bien como otro espacio desde otra lógica.

Es en el tránsito desde este espacio doméstico al espacio público ampliado donde la Pachamama se congela y estabiliza como significante para ser enunciado. Y es allí donde la trampa denunciada opera estabilizando su radicalidad, convirtiéndola en un reduccionismo folklórico de la otredad. La cuestión analítica radica más bien en tratar de comprender cómo la Pachamama opera en la cotidianidad de las comunidades aborígenes para luego ver cómo realiza su paso al espacio público ampliado. Pachamama opera aquí entonces más bien como un artefacto retórico -o artefactualismo difractario, al decir de Haraway (1999)- para dar cuenta en el espacio público moderno de prácticas otras de actuaciones que se mantienen en la oscuridad, en los repliegues de escenarios periféricos que escapan al "logos" moderno de la razón; prácticas que plantean otros "logos", otras formas más anímicas de la relación entre la "naturaleza” y la "cultura” (Descola 2012).

De este modo, sin aislar ni estabilizar los significantes, Pachamama abre la posibilidad de seguir las intersecciones entre formas diferenciadas del sentido en relación al ambiente y la cultura que convergen en la disputa por la explotación de litio en las Salinas Grandes. Un diálogo entre "Pachamámicos” y “Modérnicos” según lo entiende Escobar (2011), en el cual interpretaciones diferenciadas se confrontan por la imposición del sentido; una disputa que no puede ser entendida sino en términos históricos por hegemonías más amplias. Por ello, hablar de Pachamama no implica un punto de partida en el debate, sino uno punto de llegada. Se trata en definitiva de escapar a los etiquetamientos previos que cancelan el diálogo y abrir nuevas posibilidades para un encuentro intercultural (Segato 2007; Fornet-Betancourt 2006). La consigna política es entonces no diseccionar esos lenguajes de valoración diferentes sobre el medio ambiente (Martínez 
Allier, 2004), sino describirlos en tanto van operando en la práctica cotidiana de los pueblos indígenas.

Es en su uso y no en las definiciones académicas donde encontraremos, desde una mirada etnográfica de la experiencia colectiva originaria, el significado asignado a Pachamama. Es con estas mediaciones que se pretende entablar un diálogo (Martín-Barbero 1993). En esta línea de reflexión, dialogar con la Pachamama, en tanto imperativo político, para entender los procesos de resistencia de los pueblos indígenas en las Salinas Grandes, implica asir la complejidad de estos procesos advirtiendo los reduccionismos inherentes a nuestras propias epistemologías, en tanto herederas históricas de aquel ensamble moderno y de los procesos históricos de epistemicidio de las culturas subalternas (Barbetta 2012); implica finalmente reflexionar acerca de otros logos que convergen en la disputa, pero también en el análisis que se realiza.

\section{De logos, lugares y epistemes}

Una perspectiva decolonial que entienda los procesos de disputa territorial en Jujuy como lugares de convergencia de genealogías históricas más amplias haría mea culpa y sometería al propio análisis las epistemes que son los puntos de partida de las interpretaciones sociales, configurando desde allí un lugar crítico para desandar también lo aprendido. La radicalidad de la diferencia no sólo impone la necesidad de una reconjugación del aparto político estatal para dar lugar a un respeto por las formas otras de habitar el espacio, sino que también requiere una revisión de las epistemes que hacen el análisis. Al fin y al cabo, ambas son consecuencias del mismo proceso histórico y sus objetivos fueron similares. Entonces, la radicalidad de una diferencia impone también una revisión de las epistemes ancladas en la academia y de lo que producen en el análisis social.

En esta intersección entre ambos lugares, surgen dos núcleos problemáticos. El primero está vinculado a la flexibilidad de las epistemes de partida para pensar la diferencia sin reduccionismos ni congelamientos. Frecuentemente, lo que hacen nuestras epistemes es congelar un estado particular en un momento dado, sin ver la transitividad de lo que está ocurriendo. Y si bien hay algo que podemos aprender de los pueblos indígenas, es cómo la transitividad está en un sucediendo y no en un congelamiento particular (Tola 2012). Sin duda alguna, los estudios decoloniales, en particular el programa del Grupo Modernidad/Colonialidad, sobre la colonialidad del poder, del saber y del ser, han constituido una interesante crítica a las epistemes modernas (Lander 2000). No obstante, la fuerza centrípeta del academicismo estabilizante es tal que la radicalidad originaria del proyecto crítico se ha ido sedimentando de a poco, haciendo finalmente de estas líneas de investigación otros lugares estables y domesticados. Cabe preguntarse, entonces, si estas perspectivas críticas no han sido ecualizadas para redundar en la ecualización de la otredad. Es una pregunta necesaria y 
un riesgo que debemos advertir para que nuestros análisis no sean presos o cooptados por la lógica institucionalizante de la modernidad.

Por otra parte, el segundo núcleo problemático corresponde al análisis situacional específico que se desprende de estas reflexiones. El diálogo sólo es posible desde una conversación situada, pero también con una respuesta situada. Supone entonces la renuncia a los universales y la aceptación de un situacionismo específico desde el cual aprender. De lo que se trata, en definitiva, es de poner en tensión la idea de un pensamiento único -la mono-cultura del saber y del rigor (Santos 2006)-, pero no para anteponer otro único, sino más bien varios, muchos únicos situados en contextos específicos. Así también, se trata de visualizar las diferencias, no para generar un nuevo diálogo acabado, un nuevo techo de la discusión, sino más bien movimientos dia-lógicos. Es aquí entonces donde la radicalidad de la diferencia conmueve también nuestras epistemologías, tensionando su devenir e interpelando su estabilización. Es este el aprendizaje pendiente para continuar no sólo el análisis, sino también la militancia política por la defensa del territorio, en cuanto “intelectuales anfibios” al decir de Svampa (2007).

\section{Sospechas inconclusas}

La trampa es trampa cuando se nos presenta como único horizonte de perspectiva posible, cuando esa ficción Estado-céntrica de la ciudadanía simétrica parece ser el único umbral de expectativa posible, el único marco para la acción. La trampa es trampa cuando opera encausando la fuerza de la radicalidad, de la demanda surgida de una interpretación otra de habitar el espacio y los lugares. Y la alternativa política posible no es la negación de la ecualización en el discurso del derecho -ya que en sí mismo ésta es la forma de relación e interacción social posible-; sino que más bien una tecnología de emancipación posible requiere atravesar la nominalización ciudadana estratégicamente; conscientes de ese campo de acción para, desde adentro, dar cuenta de las contradicciones acelerando la dinámica oposicional.

Sortear la trampa de la ecualización de la diferencia requiere de un permanente ejercicio de movimiento, de desplazamiento, de corrimiento estratégico; una conciencia oposicional, flexible, móvil, diaspórica, esquizofrénica, nómada, al decir de Sandoval (2004). Allí, cuando es creado para uno el lugar de enunciación, es cuando la esencialización opera reteniendo el movimiento circunscribiéndolo, limitando las posibilidades y opciones de desplazamiento. Si estas son las opciones, las estrategias son entonces dinámicas, permanentes procesos de des-territorialización y reterritorialización (Deleuze y Guattari 2002), escapando de este modo al designio único del "logos".

La pregunta por la defensa de los territorios indígenas en Jujuy no queda respondida entonces acá, sino más bien queda en suspenso. Porque la estrategia misma resiste a plantearse una alternativa teleológica confor- 
me a un "logos" posible que "ilumine" el camino a seguir (Haraway 1999). La estrategia política -también en este texto-consiste más bien en acelerar las contradicciones, movilizando las estructuras y las interpretaciones.

En suma, la crítica aquí desplegada proviene de un proceso de normalización de la diferencia en la ecualización a través del derecho positivo como único horizonte de perspectiva. Es así que debe de entenderse el reconocimiento de algunas -y sólo algunas- políticas específicas de reconocimiento de la identidad étnica: concesiones parciales al derecho indígena como táctica de reciclado de la hegemonía dominante (Rivera Cusicanqui 2010). Esta crítica no plantea la renuncia irrestricta a ocupar ese espacio, sino más bien discute el que sea considerado como el único lugar posible para expresar y reconocer la diferencia, en tanto operación de estabilización, de esencialismo. La alternativa consiste entonces en ocupar ese lugar desde un "esencialismo estratégico", según lo propuesto por Spivak (citada en Sandoval 2004), como opción política para nuevos desplazamientos. Territorializaciones nuevas ocupando lugares, movilizando diálogos interculturales desde la interacción de "logos" no estabilizados. De esta forma, la estrategia subvierte la ecualización desandándola, desmitificándola. Son esas las opciones políticas que nos quedan por delante. 
Polis, Revista Latinoamericana, Volumen 13, $N^{\circ}$ 38, 2014

\section{Notas}

1 "Sea por miedo a la chusma o por seguir la agenda de sus financiadores, las elites se sensibilizan a las demandas de reconocimiento y de participación política de los movimientos sociales indígenas, y adoptan un discurso retórico y esencialista, centrado en la noción de “pueblos originarios”. El reconocimiento -recortado, condicionado y a regañadientes- de los derechos culturales y territoriales indígenas permitió así el reciclaje de las elites y la continuidad de su monopolio en el ejercicio del poder. [...] En tanto que la noción de "origen” nos remite a un pasado que se imagina quieto, estático y arcaico. He ahí la recuperación estratégica de las demandas indígenas y la neutralización de su pulsión descolonizadora. Al hablar de pueblos situados en el "origen” se niega la coetaneidad de estas poblaciones y se las excluye de las lides de la modernidad. Se les otorga un status residual, y de hecho, se las convierte en minorías, encasilladas en estereotipos indigenistas del buen salvaje guardián de la naturaleza” (Rivera Cusicanqui 2010:58-59).

${ }^{2}$ Véase "Piquete contra la megaminería", en Página 12 (22 de julio de 2011), disponible en http://www.pagina12.com.ar/diario/sociedad/3-172781-2011-07-22.html (consultado el 26/07/13).

${ }^{3}$ Véase Encuentro en la sal, cortometraje de Miguel Ángel Pereira (2012), disponible en http://www.lipanjujuy.com.ar/ index.php?option=com_content \&view=article \&id=61:encuentro-en-lasal\&catid=36:novedades\&Itemid=55 (consultado el 26/07/13); "Una lucha que llegó a la ONU”, en Página 12 (16 de julio de 2011), disponible en http://www.pagina12.com.ar/ diario/sociedad/3-172370-2011-07-16.html (consultado el 26/07/13).

4 Detalles del proyecto disponibles en http://www.iirsa.org/proyectos/ detalle_proyecto.aspx?h=1304 (consultado el 26/07/13).

5 Detalles del proyecto disponibles en http://www.iirsa.org/proyectos/ detalle_proyecto.aspx?h=120 (consultado el 26/07/13).

${ }^{6}$ Véase "La Corte intervendrá en un conflicto minero", en Página 12 (27 de diciembre de 2011), disponible en http:/www.pagina12.com.ar/diario/ultimas/20-184270-201112-27.html (consultado el 26/07/13); “La voz de las Salinas Grandes”, en Página 12 (28 de marzo de 2012), disponible en http://www.pagina12.com.ar/diario/ultimas/20190629-2012-03-28.html (consultado el 26/07/13).

${ }^{7}$ El Gobierno de la Provincia de Jujuy integra activamente la Organización Federal de Estados Mineros (OFEMI) de la Argentina, institución interprovincial dedicada a la promoción de actividades mineras. 


\section{Bibliografía}

Aguilar, Franco y Zeller, Laura (2012), Litio. El Nuevo Horizonte Minero. Dimensiones Sociales, Económicas y Ambientales, Centro de Derechos Humanos y Ambiente, Córdoba, Argentina.

Anaya, James (2012), Informe del Relator Especial sobre los derechos de los pueblos indígenas, Oficina del Alto Comisionado para los Derechos Humanos. Naciones Unidas.

Barabas, Alicia M. (2004), "La territorialidad simbólica y los derechos territoriales indígenas: reflexiones para el Estado pluriétnico", en Revista Alteridades, Universidad Autonoma Metropolitana Unidad Itzapalapa, México, Vol. 14, N²7, pp 105-119.

Barbetta, Pablo (2012), Ecologías de los saberes campesinos: más allá del epistemicidio de la ciencia moderna. Reflexiones a partir del caso del Movimiento Campesino de Santiago del Estero Vía Campesina, CLACSO, Buenos Aires.

Bartolomé, Miguel Alberto (2012), "Interculturalidad y territorialidades confrontadas en América Latina", en Revista RUNA, Facultad de Filosofía y Letras - UBA, Buenos Aires, Vol. XXXI, N²1, pp. 9-29.

Bourdieu, Pierre (2008), ¿Qué significa hablar? Economía de los intercambios lingüisticos, Ed. Akal, Madrid.

Chiozza, Elena Margarita y Carballo, Cristina Teresa (2009), Introducción a la geografía, Universidad Nacional de Quilmes, Bernal.

Consejo de Organizaciones Aborígenes de Jujuy [COAJ] (2012), La madre sal, Proyecto de Participación Indígena en el Desarrollo de Jujuy, San Salvador de Jujuy.

Deleuze, Gilles y Guattari, Félix (2002), Mil mesetas. Capitalismo y esquizofrenia, Pre-Textos, España.

Descola, Philippe (2012), Más allá de naturaleza y cultura, Amorrortu Editores, Buenos Aires.

Escobar, Arturo (2001), “Ecología Política de la globalidad y la diferencia”, en Héctor Alimonda (comp.), La colonización de la naturaleza, Colección Grupos de Trabajo - CLACSO, Buenos Aires, pp.59-90.

Ídem (2011), ¿’Pachamámicos” versus “Modérnicos”?, en Revista Tabula Rasa Universidad Colegio Mayor de Cundinamarca, Colombia, $N^{\circ}$ 15 pp. 265-273. 
Fornet-Betancourt, Raúl (2006), La interculturalidad a prueba, Verlagsgruppe Mainz, Aache, Alemania.

Fornet-Betancourt, Raúl (2011), "Lo intercultural: el problema de su definición", en Interculturael. Balance y perspectivas. Encuentro internacional sobre Interculturalidad, Fundación CIDOB. Barcelona, pp. 157-160.

Fraser, Nancy (1997), Iusta Interrupta: Reflexiones críticas desde la posición "postsocialista". Siglo del Hombre Editores - Universidad de los Andres, Santafé de Bogotá.

Foucault, Michel (2002), Vigilar y castigar: nacimiento de la prisión, Siglo XXI, Buenos Aires.

Bogotá: Siglo del Hombre Editores.

Gallardo, Susana (2011), "Extracción de litio en el Norte argentino. La fiebre comienza", en Revista EXACTA mente. Revista de divulgación científica, FCEN-UBA, Buenos Aires, N48, pp. 26-29.

Giddens, Anthony (1993), Las nuevas reglas del método sociológico. Críticas positivas de la sociología interpretativa, Amorrortu Editores, Buenos Aires.

Guber, Rosana (2001), La etnografía, método, campo y reflexividad, Grupo Editorial Norma. Bogotá.

Ginzburg, Carlos (2001), El Queso y los gusanos: El cosmos, según un molinero del siglo XVI, Peninsula, Barcelona.

Habermas, Jürgen (1990), Historia y crítica de la opinión pública: La transformación estructural de la vida pública, Gustavo Gili, Barcelona.

Haraway, Donna (1999), "Las promesas de los monstruos. Una política regeneradora para otros inapropiados/bles", en Revista Política y sociedad, Universidad Complutense de Madrid, Madrid, No 30, pp. 121-164.

Lander, Edgardo [Comp.] (2000), La colonialidad del saber: eurocentrismo y ciencia sociales. Perspectivas latinoamericanas, Consejo Latinoamericano de Ciencias Sociales, Buenos Aires.

Machado, Horacio; Svampa, Maristella; Viale, Enrique; Giraud, Marcelo; Wagner, Lucrecia; Antonelli, Mirta; Giarracca, Norma y Teubal, Miguel (2011), 15 mitos y realidades de la minería transnacional en la Argentina, El Colectivo - Editorial Herramientas, Buenos Aires.

Martínez Alier, Joan (2004), El ecologismo de los pobres: Conflicos ambientales y lenguajes de valoración, Icaria/FLACSO, Barcelona. 
Martín-Barbero, Jesus (1993), De los medios a las mediaciones: comunicación, cultura y hegemonía, Gustavo Gili, Barcelona.

Merlino, Rodolfo J. y Rabey, Mario A. (1993), "Resistencia y hegemonía: Cultos locales y religión centralizada en los Andes del Sur", en Revista Sociedad y Religión, Buenos Aires, N 10/11, pp. 146-166.

Mesa de Comunidades Originarias de la Cuenca de Salinas Grandes y Laguna de Guayatayoc. [MCOCSLG] (2011), Violaciones a los derechos económicos, sociales y culturales (Desc.) de las Comunidades de Salinas Grandes en el contexto de procesos de exploración y explotación de litio. Recuperado el 30 de Junio de 2013, de Oficina del Alto Comisionado para los Derechos Humanos: http:/www2.ohchr.org/english/bodies/cescr/docs/ngos/ JujuySalta_Argentina47.pdf

Murillo, Susana (2012), Prácticas científicas y procesos sociales. Una genealogía de las relaciones entre ciencias naturales, ciencias sociales y tecnologías, Editorial Biblos, Buenos Aires.

Panikkar, Raimond (2007), Mito, fe y hermenéutica, Herder, Barcelona.

Rivera Cusicanqui, Silvia (2010), Ch’ixinakax utxiwa: una reflexión sobre prácticas y discursos descolonizadores, Tinta Limón, Buenos Aires.

Rivera Cusicanqui, Silvia (2008), "El potencial epistemológico y teórico de la historia oral: de la lógica instrumental a la descolonización de la historia". En VVAA, Teoria Crítica dos Direitos Humanos, EDIPUCRS, Porto Alegre, pp. 157-178.

Sandoval, Chela (2004), "Nuevas ciencias. Feminismo cyborg y metodología de los oprimidos", en VVAA, Otras inapropiables. Feminismos desde las fronteras, Traficante de sueños, Madrid, pp. 81-106.

Santos, Boaventura de Sousa (2006), Renovar la teoría crítica y reinventar la emancipación, CLASCSO, Buenos Aires.

Santos, Milton (2000), La naturaleza del espacio. Técnica, tiempo, Razón y Emoción, Editorial Ariel, Barcelona.

Segato, Rita (2007), La Nación y sus Otros. Raza, etnicidad y diversidad religiosa en tiempos de Políticas de la Identidad, Prometeo Buenos, Aires.

Segato, Rita (2011), "Que cada pueblo teja los hilos de su historia: El pluralismo jurídico en diálogo didáctico con legisladores", en Victoria Chenaut, Magdalena Gómez, Héctor Ortiz y María Teresa Sierra (Coor.), Justicia y diversidad en América Latina. Pueblos Indígenas ante la Globalización. Centro de Investigaciones y Estudios Superiores en Antropología Social Facultad Latinoamericana de Ciencias Sociales, Ecuador, pp. 357-381. 
Souto, Patricia (2011), "El concepto de paisaje. Significados y usos en la geografía contemporanea", en En Patricia Souto (Ed.), Territorio, Lugar, Paisaje. Prácticas y conceptos básicos en geografía, Colección Libros de Cátedra - Facultad de Filosofía y Letras, UBA,. Buenos Aires.

Spivak, Gayatri Chakravorty (2011), ¿Puede hablar el sujeto subalterno?, El cuenco de plata, Buenos Aires.

Svampa, Maristela (2007), "Notas provisorias sobre la sociología, el saber académico", en Valeria Hernández y Maristella Svampa (Ed.), Gérard Althabe: Entre varios mundos. Reflexividad, conocimiento y compromiso, Prometeo, Buenos Aires.

Svampa, Maristella (2008), "La disputa por el desarrollo. Territorios y lenguajes", en Maristella Svampa, Cambio de época. Movimientos sociales y poder político, Siglo XXI, Buenos Aires.

Tola, Florencia (2012), Yo no estoy solo en mi cuerpo. Cuerpos-personas múltiples entre los Tobas del Chaco Argentino, Biblios, Buenos Aires.

Williams, Raymond (1997), Marxismo y literatura, Península, Barcelona.

Worster, Donald (2008), Transformaciones de la tierra, Coscoroba Ediciones / Biblioteca Latinoamerica en Ecología Política, Montevideo.

Zaffaroni, Eugenio (2011), La Pachamama y el humano, Ediciones Madres de Plaza de Mayo, Buenos Aires.

Zubia, Gonzalo Federico (2012), "El territorio como lugar de resistencia: opciones epistemológicas en el estudio de los conflictos sociales en las Salinas Grandes, Provincia de Jujuy", en Jornada de Becarios de la UNQ, Universdiad Nacional de Quilmes, Bernal, Quilmes.

Recibido: 15.05.2014

Aceptado: 15.07.2014 